\title{
LITOESTRATIGRAFIA PRELIMINAR PARA OS DEPÓSITOS DE ENCOSTA DO QUATERNÁRIO SUPERIOR DO PLANALTO SE DO BRASIL (MG-RJ)*
}

\author{
JOSILDA RODRIGUES DA SILVA DE MOURA** e MARIA REGINA MOUSINHO DE MEIS***
}

\begin{abstract}
A preliminary lithostratigraphy for the Upper Quaternary deposits of the MiddleLower valley of the Paraiba do Sul river is here tried, based on the systematic reproduction of some exposed sections. An special attentionisiven to the slope materials, since the colluvial deposits are considered to be highly significative within the moist tropical environments.

Three different colluvial sequences are heve identified: $a$ ) lower sequence, of Pleistocene age, is characterized by the occurrance of reddish, non-stratified colluvia which bear well developed soil structures; $b$ ) the middle sequence, dated approximately to the end of the Pleistocene and beginning of the Holocene, is constituted by yellowish, poorly stratified colluvia, bearing less significative secondary structures; $c$ ) the upper sequence, of Holocene age, is constituted by brownish-yellowish, poorly stratified colluvia.

A first attempt to relate the geometry of the rock strata to the slope morphology is also tried. The validity of the present results is to be tested in the future, when more detailed data will be available.
\end{abstract}

INTRODUÇÃo No domínio extratropical, o estudo do Quaternário continental vem sendo tentado pelo emprego de métodos geomorfológicos (cronologia da desnudação) e a partir da análise da sequêência deposicional, com enfoque estratigráfico. A definição das relaçð̌es estratigráficas existentes entre as seqüências de corpos glaciais, fluviais, lacustres e eóleos tem fornecido os controles considerados como os mais seguros para a reconstituição dos eventos quaternários (Flint, 1965; Fairbridge, 1969; Morrison, inédito; etc.). Dentro desse quadro, entretanto, pouca atenção vem sendo dada ao domínio das encostas e às fácies coluviais, pois os colúvios são muito fragmentários e pouco representativos dentro das sequências sedimentares continentais observadas nas latitudes médias.

Nos planaltos tropicais, porém, os colúvios representam uma cobertura quase que generalizada da paisagem e qualquer tentativa para compreender a sedimentaçăo quaternária precisa ancorar-se substancialmente numa integração dos estudos de corpos coluviais aos de origem fluvial e lacustre. A importância que assumem os depósitos de encosta, já mencionada por Bigarela et al. (1965), Zonneveld (1975) e outros autores, é refletida em toda uma série de trabalhos publicados sobre o tema nas últimas dezenas de anos. Entretanto as tentativas para elaboração de estudos sistemáticos objetivando o estabelecimento de uma coluna estratigráfica são ainda escassas.

Uma rápida revisão bibliográfica sobre o Quaternário Superior no planalto brasileiro demonstra que por longo tempo as observaçðes se concentraram na descrição de sequências litológicas relativamente sim- ples, geralmente denominadas na literatura como o "complexo da linha de seixos". A seqüência pode ser sucintamente descrita como constituída, em sua base, pelas rochas do substrato geológico fortemente intemperizadas. Em discordância sobre o elúvio aparece uma concentração de seixos (stone-line), geralmente de quartzo anguloso e que se apresenta por sua vez recoberta por um manto coluvial de textura fina e estrutura maciça. Tanto a linha de seixos como a capa de materiais finos vêm sendo descritas como acompanhando em subsuperfície a topografia da encosta atual (Setzer, 1949; Tricart, 1958; Cailleux e Tricart, 1959; Lehmann, 1959; Ab'Sạber, 1962; Cailleux, 1966; Troll, 1969; Brown Jr. e Ab'Saber, 1979; etc.).

Alguns autores tomaram a "linha de seixos" como um horizonte guia estratigráfico, que representaria uma divisória separando os eventos pré e pós-pavimentação detrítica. Face a essa tendência e à concepção de que a "linha de seixos" caracterizaria um episódio de clima seco, passou ela imperceptivelmente a receber um significado cronoestratigráfico. Esse esquema simples já vem sendo questionado desde o trabalho de Bigarella (1964), no qual é levantada a possibilidade de que o "complexo da linha de seixo" poderia resultar de retrabalhamentos sucessivos, pouco extensos e de significado estratigráfico pouco nítido. Essa observação foi posteriormente confirmada por outros autores no Brasil (Mousinho e Bigarella, 1965; Penteado, 1969; Meis et al., 1975; Meis e Monteiro, 1979; etc.) e na África (Folster, 1969; Ojunaga e Wirth, 1977; etc.).

A revisão dos trabalhos que vêm sendo executados no Brasil a propósito dos depósitos de encosta parece

\footnotetext{
* Trabalho efetuado sob os auspícios da FINEP/UFRJ, CNPq e CEPG/UFRJ

** Instituto de Geociências, UERJ - Rio de Janeiro

*** Instituto de Geociências, UFRJ - Rio de Janeiro
} 
deixar clara a necessidade de estabelecer uma primeira litoestratigrafia para o Quaternário Superior, com ênfase no estudo das sequiências aluviais e coluviais. Por outro lado, torna-se patente que só uma reconstituição da estratigrafia dos colúvios poderá levar, no futuro, a uma melhor compreensão da problemática envolvida pela evolução das encostas regionais. No presente texto, pretende-se esboçar uma litoestratigrafia preliminar para os depósitos de encosta ligados aos ambientes de "rampas" (terminologia proposta por Meis e Monteiro, 1979) dentro do médio-baixo vale do rio Paraíba do Sul. Acredita-se que a coluna litoestratigráfica será básica para futuros estudos de caráter bioestratigráficos e poderá levar a uma melhor reconstituição da curva paleoclimática e à cronoestratigrafia do Quaternário Superior regional.

METODOLOGIA Uma seqüência quaternária continental completa dificilmente será encontrada, pois a sedimentação é caracteristicamente descontínua e fragmentária no espaço e controlada pelas irregularidades do relevo. Em conseqüência, o estudo do Quaternário continental encontra-se dependente de um desenvolvimento metodológico próprio, devendo fundamentar-se no inter-relacionamento da Estratigrafia com a Geomorfologia.

No médio-baixo vale do rio Paraíba do Sul busca-se encontrar as relaçôes entre a geometria do relevo e a seqüência de depósitos de encosta. O reconhecimento prévio da dinâmica das rampas (Meis e Monteiro, 1979) leva a que a Geomorfologia guie a amostragem das seções a serem representadas. Entretanto o controle estratigráfico é fundamental, pois se acredita representar ele um complemento indispensável à definição de uma morfoestratigrafia. Considera-se perigoso o estabelecimento de uma cronologia de eventos tendo como base única a cronologia de desnudação; isso torna-se ainda mais precário quando a sedimentação mergulha pluriaxialmente, como é o caso normal nos ambientes de rampas.

A escolha das seçðes expostas representadas em detalhe fundamentou-se tanto na ocorrência de seqüências estratigráficas passíveis de revelar as relaçoes entre os diferentes litossomas, em ambiente de baixa encosta, como na associação das unidades deposicionais a formas topográficas de detalhe dentro dos "complexos de rampas".

CONDIÇÕES REGIONAIS A área em estudo situase entre os paralelos de $21^{\circ}$ e $22^{\circ} \mathrm{S}$ e os meridianos de $42^{\circ}$ e $44^{\circ} \mathrm{WGr}$, englobando parte do vale do Paraíba do Sul assim como porções limítrofes da bacia do Doce. $O$ trecho pesquisado corresponde ao chamado médio-baixo vale do rio Paraíba do Sul (Fig. 1).

Brandalise et al. (1976) identificaram duas grandes unidades de mapeamento dentro do substrato précambriano regional, tendo como base suas características litológicas e estruturais: a) Associação Barbacena, constituída com predomínio de micaxistos, quartzitos, gnaisses, basitos e ultrapasitos; e $b$ ) Associação Paraíba do Sul, caracterizada com predomínio de migmatitos e com freqüentes ocorrências de charnockitos.
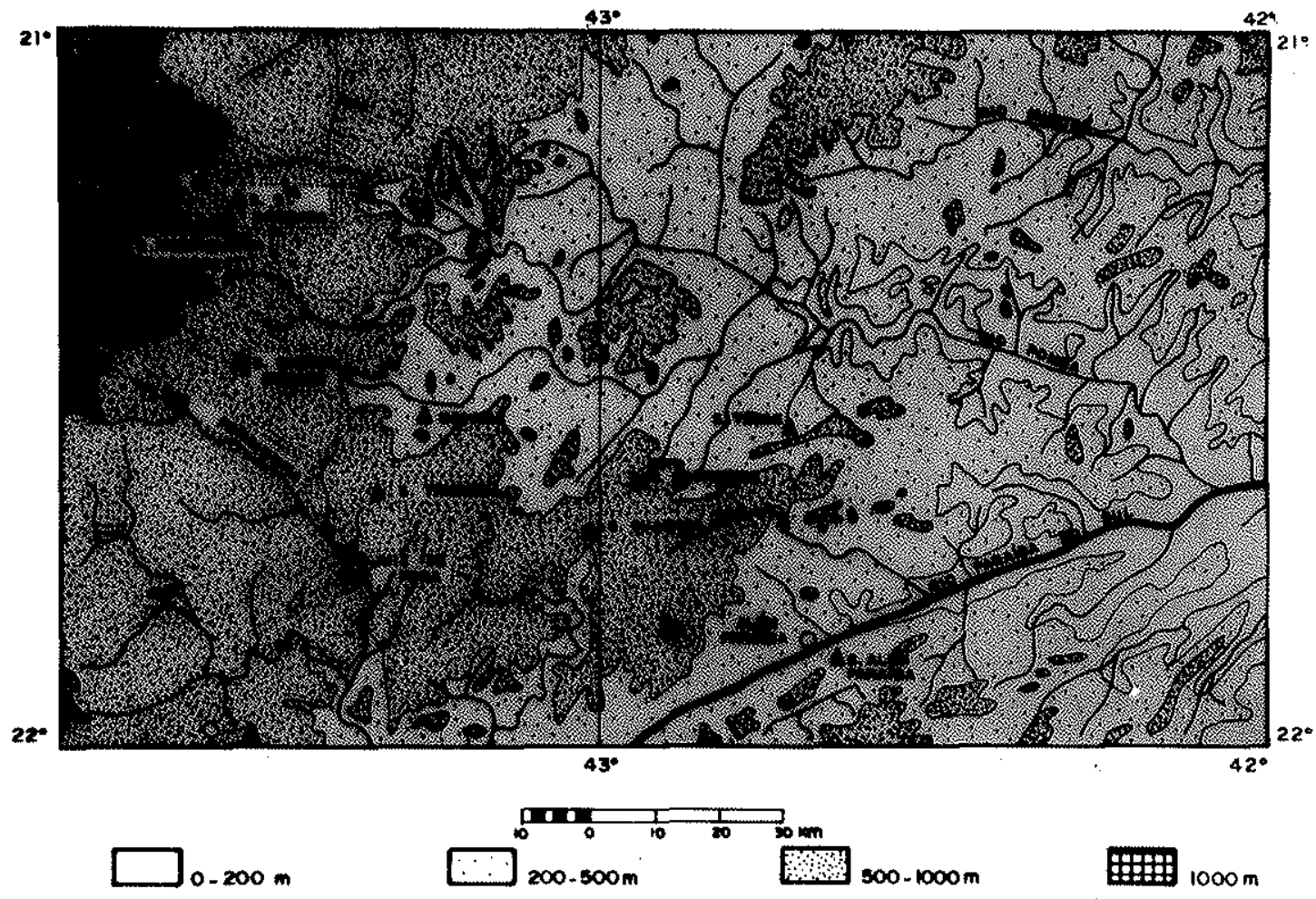

Figura 1 - Área de estudo e localização das seções expostas representadas 
A área está englobada na reçiăo denominda por Al. meida (1976) de região dobrada sudeste, onde inúmeras falhas de rejeito direcional resultaram de uma tectônica de blocos posterior aos dobramentos do ciclo brasiliano (Hasui et al., 1976). Reativações mais recentes encontraram expressão máxima no Eocretáceo, a partir do qual a região passou a ser sujeita a movimentos verticais que provocaram tração da crosta por falhas normais nas direções das linhas de fraqueza pré-cambrianas (Asmus e Ferrari, 1978). Ao rompimento segundo falhas normais seguiu-se uma estruturaçấo dos blocos escalonados que deram origem às serras do Mar e Mantiqueira bem como às bacias terciárias de Volta Redonda, Resende, Taubaté etc.

A morfologia do vale do Paraíba é considerada na literatura como apresentando o predomínio das paisagens de colinas em mares de morros (De Martonne, 1944; Ruellan, 1951; King, 1965; etc.). Os domínios de formas rebaixadas são interrompidos localmente pơr serras e de graus de planaltos: as serras seguem grosso modo as direções estruturais dóminantes do substrato cristalino. Os degraus de planalto vêm sendo interpretados como possíveis compartinentos estruturais e ligados ás reativaçôes tectônicas do final do Mesozóico e início do Cenozóico (Washburne, 1939; Freitas, 1951; Almeida, 1977; etc.). De acordo com De Martonne
(1944), King (1965), Bigarella et al. (1965) e outros autores, alguns desses degraus do relevo poderiam resultar de uma evolução erosiva policíclica.

O clima da regiăo estudada pode ser caracterizado pela sazonalidade das precipitaçőes (verões úmidos e in. vernos secos). As áreas serranas individualizam-se por aprẹsentarem índices pluviométricos excepcionalmente elevacios durante a estação chuvosa, disso resultando totais anuais de chuva que podem ultrapassar os $2000 \mathrm{~mm}$. Nas áreas rebaixadas, os totais anuais oscilam entre 1200 e $1500 \mathrm{~mm}$, com índice de precipitação menos acentuado durante o verão. As temperaturas médias anuais variam com a altitude: as áreas serranas podem ser definidas como mesotérmicas, registrando temperaturas médias anuais entre $17^{\circ} \mathrm{C}$ e $21^{\circ} \mathrm{C}$ enquanto as regioes rebaixadas apresentam médias de temperaturas anuais variando entre $21^{\circ} \mathrm{C}$ e $24^{\circ} \mathrm{C}$.

RESULTADOS E DISCUSSÕES Foram representa das seçôes estratigráficas nas localidades de Guarará, Além-Paraíba, Santa Bárbara do Tugúrio, Tebas, Barbacena (Clinia Mantiqueira), Triqueda, Goianá, Sítio Cachoeira (em Bicas) e Santos Dumont (Fig. 2). A análise das seções visou à obtenção de sequências litoestratigráficas representativas para o diagnóstico da dinâmi-
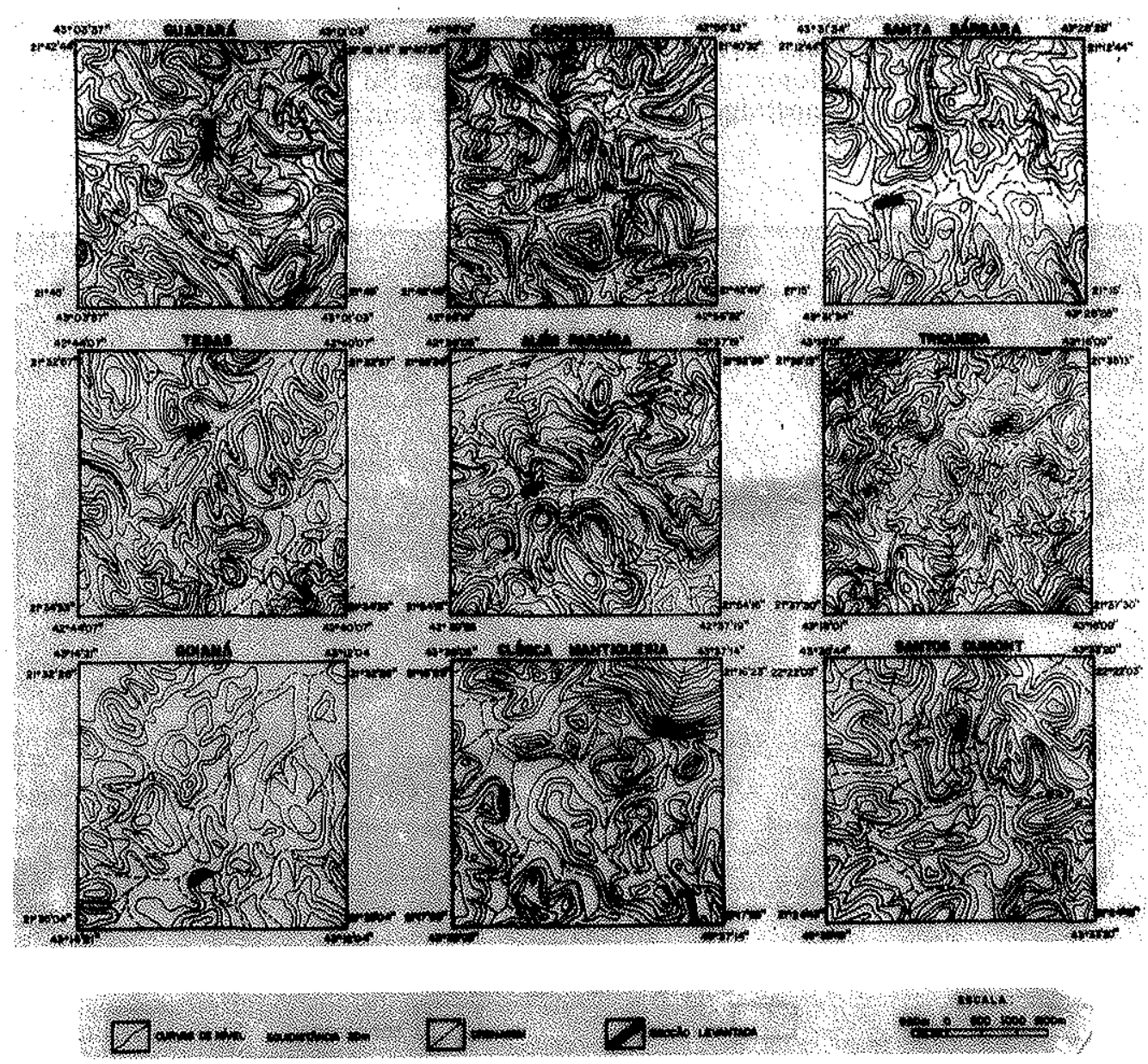

Figura 2 - Localização na encosta das seções levantadas 
Tabela 1 - Coluna litoestratigráfica preliminar para o Quaternário Superior do médio-baixo vale do rio Paraíba do Sul

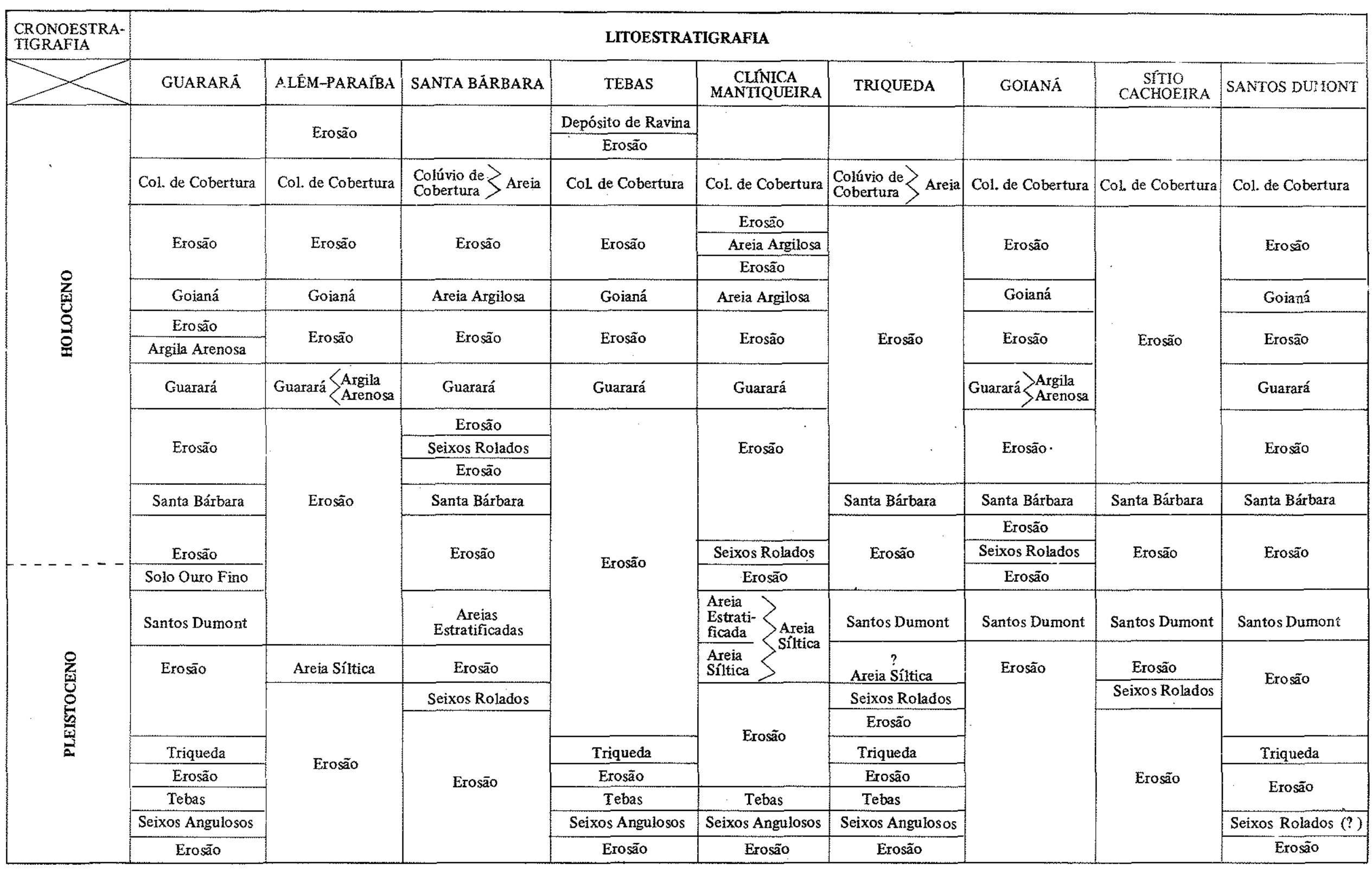


ca de sedimentação do Quaternário Superior em ambiente de encosta. Os resultados coligidos mostraram uma série de convergências possibilitando, assim, a elaboração de uma coluna litoestratigráfica preliminar para o complexo coluvial da regiåo (Tab. 1). As seqüências obtidas vieram a mostrar a ocorrência de unidades colu- viais singulares, de significado possivelmente local, e a identificação de outras de aparente significado regional. Estas últimas desempenharam um importante papel no estabelecimento de um arcabouço litoestratigráfico para a área em estudo e, por essa razão, foram analisadas com maior detalhamento (Figs. 3, 4 e 5).

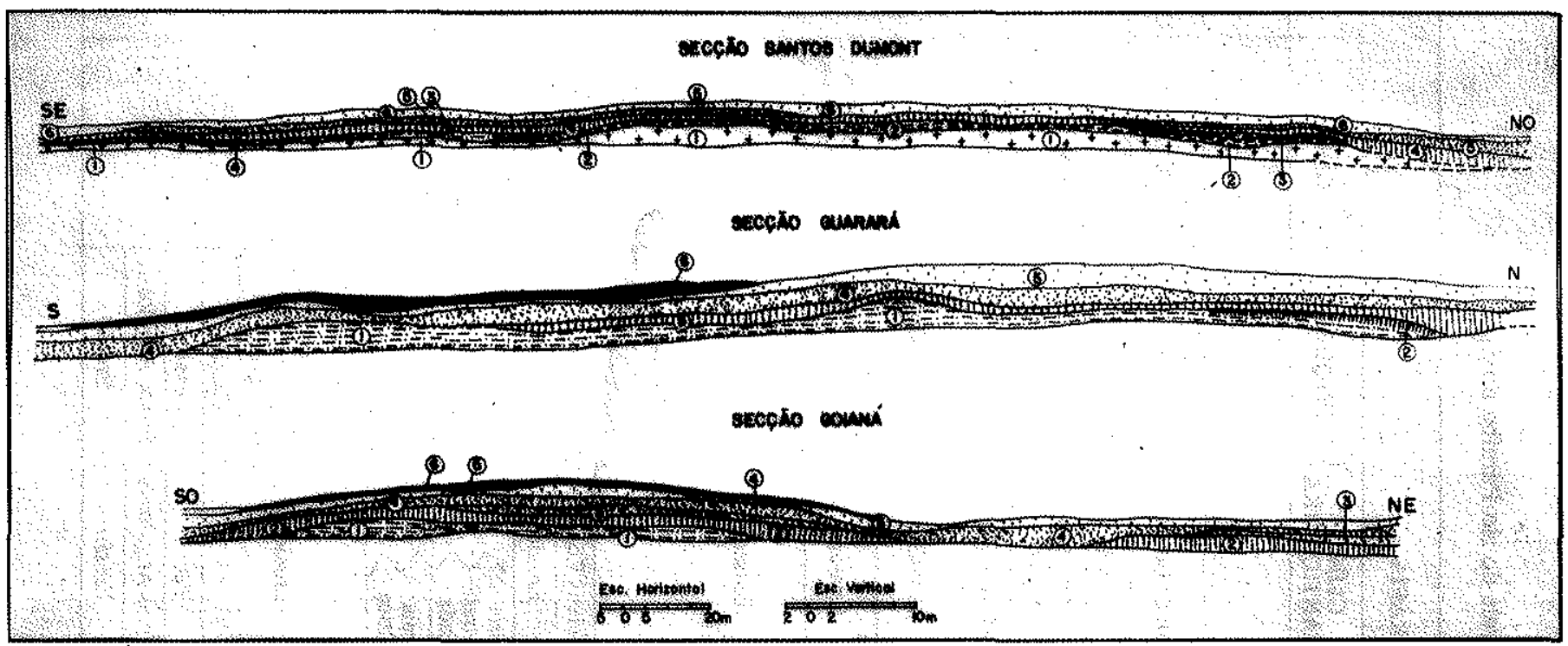

Figura 3 - Seção Santos Dumont, estrada que liga Juiz de Fora a Barbacena, $7 \mathrm{~km}$ depois de Santos Dumont. 1. Micaxisto alteradó. 2. Material argiloso de cor vermelho-amarelada (7.5YR-5/8), mal selecionado. Contém esparsos fragmentos de quartzo de até $5 \mathrm{~cm}$ de diâmetro, sendo frequentes os grânulos de até $1 \mathrm{~cm}$ de diâmetro (fácies Triqueda). 3. Material argilo-arenoso de cor amarela (10YR-7/8) com grânulos pouco freqüentes de quartzo anguloso inferiores a $2 \mathrm{~mm}$ de diâmetro. Aparentemente não apresenta estrutura primária e apresenta baixo selecionamento (fácies Santos Dumont). 4. Material argilo-arenoso com silte de for amarela (10YR-7/8) com grânulos freqüentes de quartzo angulosos inferiores a $5 \mathrm{~mm}$. Apresentam-se mal selecionadas e com indícios de estratificação plano-paralela (fácies Santa Bárbara). 5. Material arenoso fino com silte de cor amarelo-avermelhada (7YR-6/6) relativamente selecionado, apresentando indícios de estratificação plano-paralela (fácies Guarará). 6. Material arenoso com silte de cor marrom-amarelada (10YR-5/8) contém freqüentes grânulos de quartzo inferiores a $2 \mathrm{~mm}$. Relativamente bem selecionado e com indícios de estratificação plano-paralela (fácies Goianá)

Seção Guarará: Corte localizado a $500 \mathrm{~m}$ do entroncamento da estrada que liga Bicas a Leopoldina (3,5 km depois de Bicas) com a estrada para Guarará. 1. Material argilo-arenoso amarelo (10YR-7/8) com grânulos pouco freqüentes de quartzo anguloso até $2 \mathrm{~mm}$. Sem estrutura visivel e mal selecionado (fácies Santos Dumont). 2. Paleossolo. Horizonte A orgânico solo Ouro Fino. 3. Material síltico-arenoso cor amarelo-avermelhada (7.5YR-7/8) com freqiètes grânulos de quartzo e feldspato de diâmetro inferior a $2 \mathrm{~mm}$. Apresenta indícios de estratificaçăo plano-paralela e baixo selecionamento (fácies Santa Bárbara). 4. Material arenoso fỉno com silte de cor amarelo-avermelhada (7.YR-7/8) relativamente selecionado e apresenta indícios de estratificaçăo plano-paralela (fácies Guarará). 5. Material arenoso com silte marrom-amarelado (10YR-5/8) contém grânulos pouco freqüentes de quartzo inferiores a $2 \mathrm{~mm}$. Apresenta alguns indícios de estratificação plano-pararela e baixo selecionamento (fácies Goianá). 6 . Material argiloarenoso marrom-amarelado (10YR-5/6), poucos grânulos de quartzo anguloso inferiores a 2 mm. Aparentemente sem estrutura e baixo selecionamento (colúvio de cobertura)

Seção Goianá, estrada que liga Juiz de Fora a Piraúba 1 km depois de Goianá. 1. Material argilo-arenoso de cor amareloavermelhada (7.5YR-7/8) contém grânulos de quartzo anguloso pouco frequientes inferiores a $2 \mathrm{~mm}$. Aparentemente apresentam estruturas maciças e muito baixo selecionamento (fácies Santos Dumont). 2. Material argilo-arenoso com silte de cor. amareloavermelhada (7.5YR-7/8). Apresenta frequientes grânulos de quartzo e feldspato de diâmetro inferiores a $5 \mathrm{~mm}$. Mal selecionado e com indícios de estratificação plano-paralela (fácies Santa Bárbara). 3. Material areno-síltico de cor amarelo-avermelhada (7.5YR-6/6) com fragmentos de quartzo anguloso pouco freqüentes. Apresenta indícios de estratificação plano-paralela. 4. Material arenoso fino com silte, amarelo-avermelhado (7.5YR-7/6). Apresenta-se relativamente bem selecionado e com indicios de estratificação plano-paralela (fácies Guarará). 5. Material arenoso com silte marrom-amarelado (10YR-5/8). Contendo grânulos pouco freqüentes de quartzo inferiores a $2 \mathrm{~mm}$. Apresenta baixo selecionamento e indícios de estratificação plano-paralela (fácies Goianá). 6. Material argilo-arenoso marrom (10YR-7/8) com bastante grânulos de quartzo angulosos de diâmetro inferiores a 5 mm, muito mal selecionado (colúvio de cobertura) 


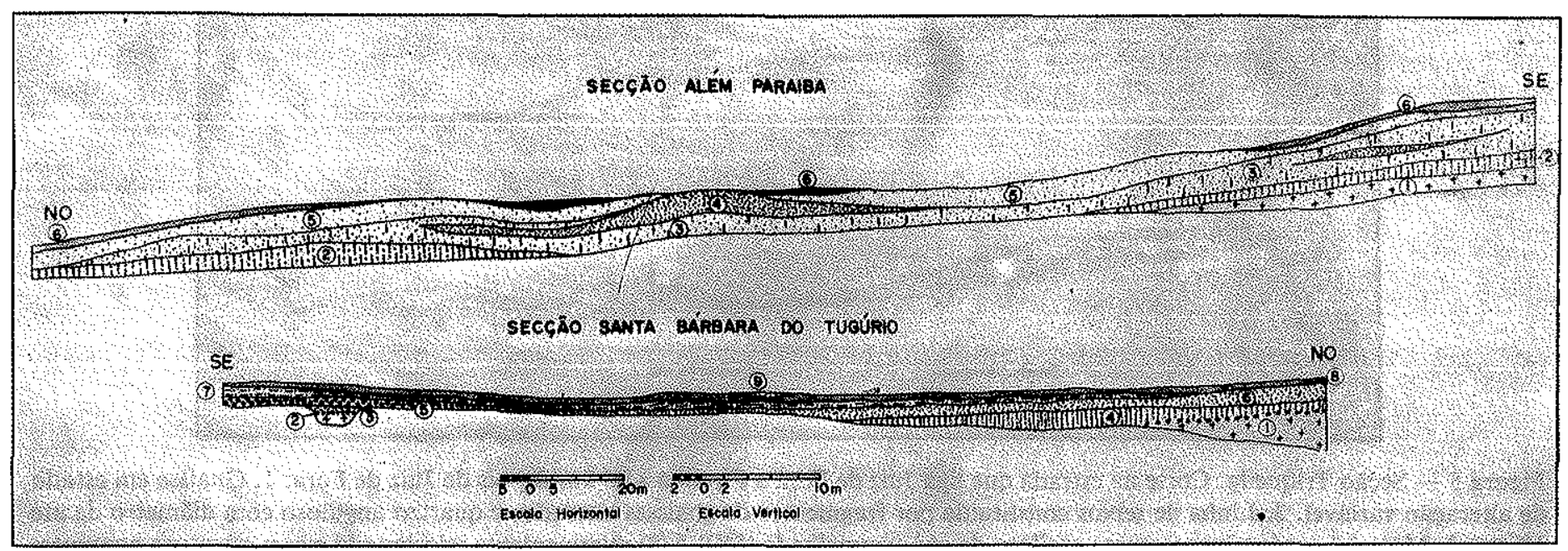

Figura 4 - Seção Além-Paraíba localizada no $\mathrm{km} 3$ da estrada que liga Além Paraíba a Carmo. 1.Gnaisse alterado. 2. Material síltico de cor amarelo-avermelhada (10YR-6/6) contendo grânulos freqüentes de quartzo anguloso inferiores a $2 \mathrm{~cm}$, aparentemente sem estrutura visível e mal selecionado. 3. Material areno-síltico de cor amarela (10YR-7/8) contém grânulos de quartzo angulosos pouco freqüentes inferiores a $5 \mathrm{~mm}$. Apresenta indícios de estratificação plano-paralela e de baixo selecionamento. 4. Material arenoso fino com silte de cor amarelo-avermelhada (10YR-6/6) aparentemente bem selecionado, apresentando indícios de estratificação plano-paralela (fácies Guarará). 5. Material arenoso com silte de cor marrom-amarelado (10YR-6/8) contém grânulos pouco freqüentes de quartzo angulosos de diâmetro inferiores a $2 \mathrm{~mm}$. Apresenta relativa seleção e indícios de estratificação planoparalela (fácies Goianá). 6. Material areno-argiloso de cor marrom-amarelada (10YR-5/4) contém poucos grânulos de quartzo anguloso inferiores a $2 \mathrm{~mm}$. Aparentemente sem estrutura visível e mal selecionado (colúvio de cobertura)

Seção Santa Bárbara do Tugúrio, km 15 da estrada que liga Mercês a Santa Bárbara do Tugúrio. 1. Gnaisse alterado. 2. Concentração de seixos quartzo arredondados de diâmetro relativamente homogêneo em torno de $10 \mathrm{~cm}$, embutidos numa matriz arenosa pouco significativa. 3. Material areno-siltico de cor vermelha (10YR-4/8), relativamente bem selecionado. Apresenta indícios de estratificação plano-paralela. 4. Concentração de seixos de quartzo subarredondados de diâmetro até $15 \mathrm{~cm}$, predominando os inferiores a $10 \mathrm{~cm}$, embutidos numa matriz arenosa grosseira síltica. 5. Material argilo-síltico-arenoso de cor amarela (10YR-7/8) com grânulos freqüentes de quartzo inferiores a $5 \mathrm{~mm}$, mal selecionado e sem estrutura visível (fácies Santa Bárbara). 6 . Concentração de seixos de quartzo arredondados de diâmetros variados até $15 \mathrm{~cm}$, com matriz arenosa grosseira pouco significativa. 7 . Material areno-síltico com argila de coloração amarelo-avermelhada (7.5YR-7/8), relativamente bem selecionado, com indícios de estratificação plano-paralela (fácies Guarará). 8. Material areno-argiloso de cor marrom-amarelada (10YR-5/3) contendo grânulos de quartzo angulosos inferiores a $2 \mathrm{~mm}$, baixo selecionamento. Apresenta indícios de estratificação plano-paralela. 9. Material arenoargiloso marrom (10YR-5/3) com grânulos de quartzo inferiores a $3 \mathrm{~mm}$, muito mal selecionado e sem estrutura visível (colúvio de cobertura)

Unidade Tebas Apresenta-se geralmente com uma geometria lenticular, sendo as lentes pouco espessas e de pequena extensão. Os materiais são predominantemente argilosos, contendo esparsos alguns grânulos de quartzo angulosos; os teores em feldspato variam entre $11 \% \mathrm{e}$ $3 \%$. A coloração é de amarelo-avermelhada a vermelhovivo dependendo do teor de umidade e a estrutura mostra-se sempre maciça. Pode-se documentar sua ocorrência em inconformidade sobre o substrato précambriano alterado. $\mathrm{O}$ plano de descontinuidade é geralmente marcado por um alinhamento de clásticos grosseiros, predominando os fragmentos de rocha de litologias variáveis e em avançado grau de alteração (micaxistos, gnaisses, quartzitos etc.) além do quartzo anguloso. $\mathrm{O}$ diâmetro dos rudáceos apresenta-se normalmente inferior a $20 \mathrm{~cm}$. A unidade Tebas encontra-se geralmente truncada pelos sedimentos da unidade Triqueda.
Unidade Triqueda Encontra-se representada por camadas lenticulares relativamente pouco espessas de sedimentos argilosos com teores variáveis de areias e siltes, contendo freqüentes grânulos (menores de $4 \mathrm{~mm}$ ) e pequenos seixos de quartzo anguloso de diâmetros geralmente inferiores a $5 \mathrm{~cm}$ dispersos caoticamente dentro da matriz fóna de estrutura maciça. Os teores em feldspato variam entre $9 \%$ e $2 \%$. Sua coloração é vermelhoamarelada, mostrando sinais de forte mosqueamento pelos óxidos de ferro.

Repousa em contato erosivo sobre as argilas de fácies Tebas. O contato entre as duas fácies é acompanhado por um alinhamento descontínuo de seixos de quartzo anguloso e com diâmetros de até $5 \mathrm{~cm}$. É truncada por uma concentração de seixos subangulosos e subarrendondados de quartzo, parcialmente envoltos em matriz arenosa (intact but disrupted framework, de acordo com a terminologia de Pettijohn, 1957) assim como mam 


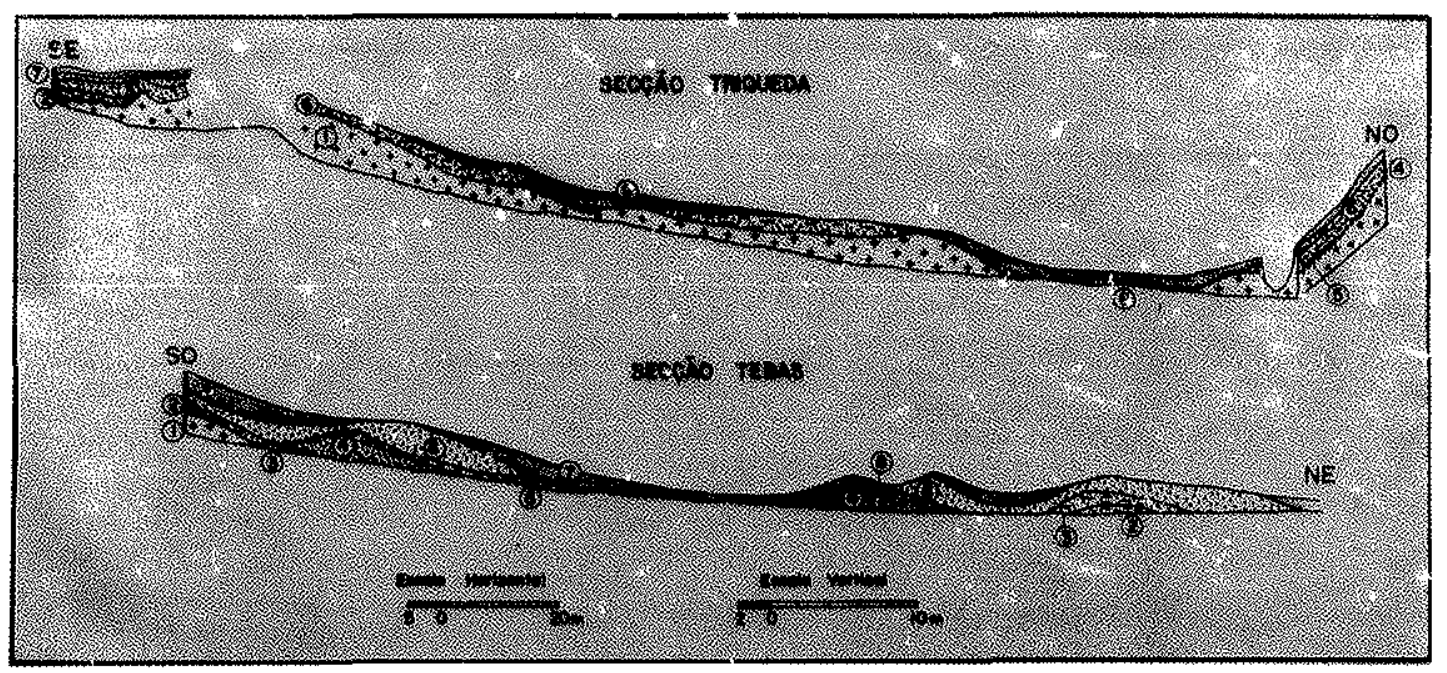

Figura 5 - Seção Triqueda. Corte na estrada que liga Juiz de Fora a Piraúba a $20 \mathrm{~km}$ depois de Juiz de Fora. 1. Gnaisse em estado de alteração variável. 2. Linha de seixos constituída por fragmentos de gnaisses alterados e quartzo anguloso com diâmetro de até $15 \mathrm{~cm}$. 3. Material predominantemente argiloso de cor avermelhada (5YR-6/8) relativamiente selecionado e sem estrutura aparente, contendo grânulos esparsos de quartzo anguloso de diâmetro inferior a $1 \mathrm{~cm}$ (fácies Tebas). 4. Material argilo-arenoso de cor vermeIha amarelada (7.YR-6/8), mal selecionado. Apresenta esparsos fragmentos de quartzo anguloso inferiores a $5 \mathrm{~cm}$, sendo mais frequèntes os grânulos de até $1 \mathrm{~cm}$ de diâmetro (fácies Triqueda). 5 . Cascalheira constituida por seixos de quartzo rolado de diâmetros inferiores a $15 \mathrm{~cm}$, predominando os menores de $10 \mathrm{~cm}$ intact but disrupted framework. A matriz é areno-síltico amarelada com raros fragmentos de quartzo anguloso. 6. Material argilo-síltico de cor amarelo-avermelhada (5YR-6/8) relativamente selecionado, com raros grânulos de quartzo e feldspatos de diâmetros inferiores a $5 \mathrm{~mm}$. 7. Material argilo-arenoso de cor amarela (10YR-7/8) com grânulos pouco freqüentes de quartzo inferiores a $2 \mathrm{~mm}$, aparentemente sem estrutura e mal selecionado (fácies Santos Dumont). 8. Areia grosseira, de cor marrom (10YR-5/3), muito mal selecionada, apresentando seixos de quartzo de até $3 \mathrm{~cm}$ de diâmetro. 9. Material arenoso argila de cor marrom (10YR-5/3) com raros grânulos de quartzo menores de 3 mm, mal selecionado sem estrutura primária visível (colúvio de cobertura)

Seção Tebas. Corte localizado a $10 \mathrm{~km}$ do entrocamento da estrada que liga Além Paraíba a Leopoldina com a estrada para Tebas (Fazenda Bela Aurora). 1. Gnaisse de textura fina alterado. 2. Material argiloso de cor amarelo-avermelhada (25YR-6/4) relativamente selecionado e não apresenta estrutura visível, contendo grânulos esparsos de quartzo anguloso de diâmetro inferior a $1 \mathrm{~cm}$ (fácies Tebas). 3. Material argilo-arenoso de cor vermelho-amarelada (5YR-5/8), mal selecionado e sem estrutura visivel. Contém frequentes grânulos de quartzo anguloso de até $1 \mathrm{~cm}$ e esparsos fragmentos de quartzo inferiores a $5 \mathrm{~cm}$ (fácies Triqueda). 4 . Material arenoso com silte cor amarelo-avermelhada (7.YR-6/6) relativamente bem selecionado, apresenta indícios de estratificação plano-paralela (fácies Guarará). 5. Argila amarela com areia, contendo fragmentos de rocha inferiores a $5 \mathrm{~cm}$. 6 . Material arenoso com argila marrom-amarelado (10YR-5/4) contém raros grânulos de quartzo anguloso relativamente bem selecionado e apresentando indícios de estratificação plano-paralela (fácies Goianá). 7. Material argilo-arenoso (areia média a grosseira) marrom forte (7.5YR-5/8) mal selecionado e sem estrutura visível contém grânulos de quartzo anguloso inferiores a 3 mm (colúvio de cobertura). 8. Material arenoso muito mal selecionado rico em grânulos e pequenos seixos de quartzo anguloso e sem estrutura (depósito de ravina)

teriais areno-síltico-argilosos avermelhados. Esses depósitos interpõem-se, localmente, às unidades Triqueda e Santos Dumont.

A unidade Triqueda tem importante significado regional e parece apresentar, em alguns locais, espessuras bem superiores às mensuradas durante o levantamento das secçð̃es.

\section{Unidade Santos Dumont É representada por cama-} das lenticulares cujas espessuras podem ultrapassar $1,50 \mathrm{~m}$. Trata-se de materiais argilo-síltico-arenosos, maciços, contendo alguns esparsos grânulos de quartzo anguloso e feldspato bastante alterado. $\mathrm{Na}$ fração arenosa, os teores em feldspato oscilam entre $5 \%$ e $2 \%$. A coloração é amarela, tendendo a amarelo-avermelhada face à presença de nódulos de mosqueamento pelcs óxidos de ferro.
A localidade de Santos Dumont mantém contato basal erosivo com a unidade Triqueda, acompanhado por alinhamentos de grânulos de quartzo. Encontra-se truncada pela unidade Santa Bárbara. Apesar de ambos os materiais mostrarem certa semelhança quanto à coloração, propriedades textuais e estruturais - o que torna difícil uma identificação baseada nas características puramente faciológicas - , puderam ser definidas como unidades estanques dentro da coluna litoestratigráfica pela análise detalhada dos planos do contato. Na seção de Guarará, o contato é marcado pelo aparecimento de um paleo-horizonte A (solo Ouro Fino).

Deve-se salientar, finalmente, que a unidade Santos Dumont parece possuir um significado regional: aparece não apenas em seis a nove localidades analisadas no médio-baixo vale do rio Paraíba do Sul mas também no médio vale do rio Doce. 
Unidade Santa Bárbara é constituida por camadas (até $2 \mathrm{~m}$ dée espessura) de sedimentos argilo-sílticoarenosos de coioração que varia entre amarela e amarelo-avermelhada devido à presença de alguns nódulos de rosquearaento pelos óxidos de ferro. Nas frações arenosas, os tcores em feldspato são sempre inferiores a $5 \%$. A frequiência relativamente elevada de grânulos de quartzo anguloso - de diâmetros inferiores a $4 \mathrm{~mm}$ - confere-lhe um aspecto de baixo selecionamento. O material anresenta, outrossim, indícios de uma estratificação plano-paralela incipiente.

Esta unidade repousa em contato erosivo sobre a unidade Santos Damont e é geralmente truncada pelos depósitos da unidade Guarará. Na localidade-tipo, entretanto, os dois colúvios são separados por uma cascatheira constituída por seixos de quartzo subangulosos a subarredondados, de diâmetros inferiores a $10 \mathrm{~cm}$ e relativamente pobre em matriz fina (intact but disrupted framework).

Unidade Guarará Foi caracterizada como um corpo sedimentar de ambiente de encosta, de forma lenticular e cuja espessura pode atingir cerca de $1 \mathrm{~m}$. Trata-se de sedimentos finos com teores variáveis de siltes e areias finas, e coloração amarelo-avermelhada. Os teores em feldspato nunca ultrapassam $3 \%$. A pobreza em clásticos mais grosseiros confere-lhe um aspecto relativamente homogêneo e bem selecionado. Pode apresentar localmente indícios de uma estratificação plano-paralela.

A localidade-tipo repousa em contato erosivo nítido sobre os depósitos argilo-arenosos aqui denominados unidade Santa Bárbara. O limite superior da unidade Guarará é sempre brusco e erosivo, sendo superposta pela unidade definida como Goianá. Ocasionalmente, intercalam-se areias argilosas consideradas como de significado local.

Unidade Goianá Associa-se a camadas espessas e de forte continuidade espacial, constituídas por sedimentos finos, predominantemente argilo-síltico-arenosos e contendo grânulos angulosos esparsos de quartzo, de diâmetro inferior a $2 \mathrm{~mm}$. Os teores em feldspato oscilam entre $1 \%$ e $2 \%$. Sua coloração é marrom-avermeIhada e apresentaj indícioside estratificação plano-paralela. Os contatos inferiores e superiores da unidade Goianá são sempre bruscos e erosivos, jaz sobre a unidade Guarará e é recoberta pelo colúvio de cobertura. Ao longo dos planos de contato observam-se sempre concentrações milimétricas de grânulos de quartzo subangulosos e de fragmentos das rochas do embasamento bastante alteradas.

A unidade Goianá parece ter importante significado regional e talvez represente um dos últimos registros da evolução das encostas da região antes dos desequilíbrios provocados pela ocupação humana.

Colúvio de cobertura Esta unidade corresponde a um capeamento extensivo de ocorrência bastante generalizada nas seções em estudo. Apresenta espessura geralmente pequena, tornando-se mais expressiva nos ambientes de fundos de depressöes. Não chega a apresentar uma homogeneidade aparente: de estrutura maciça, pode mostrar sensíveis variaçðes no diâmetro de grão predominante.
Apesar de truncar localmente a unidade Coianá, pode-se dizer que é encontrado indiscriminadamente sobre as demais unidades do complexo coluvial estudado. Nas seçōes de Tebas e Além-Paraíba, verifica-se, por outro lado, que o colúvio de cobertura foi afetado por episódio de retomada de erosão posterior: em Tebas, encontra-se ravinado, observando-se pequena gully totalmente preenchida por detritos heterométricos a imaturos do ponto de vista mineralógico. Em AlémParaíba, observa-se atualmente a preservação de apenas alguns testemunhos isolados do colúvio de cobertura ao longo das encostas.

$E$ interessante notar que, no contato basal desse colúvio, ocorrem, com freqüência, fragmentos de madeira totalmente carborizados. Poderiam vir a ser considerados como um tipo de made-land (terminologia de Willman e Frye, 1970) e, neste caso, constarão da coluna apenas informalmente.

Os resultados obtidos evidenciam uma sedimentação com características relativamente homogêneas nas encostas estudadas (este fato corna-se importante pois a área pesquisada é relativamente extensa, com mais de $1000 \mathrm{~km}^{2}$, e recobre uma parte expressiva do planalto sudeste do Brasil). Do ponto de vista textural, as unidades coluviais tendem a ser constituídas por materiais areno-argilosos e argilo-arenosos, mal selecionados e com eventuais enriquecimentos em grânulos ou siltes. Do ponto de vista mineralógico, trata-se de depósitos maduros mostrando nas frações arenosas um franco predomínio do quartzo sobre os feldspatos. Deve-se notar, entretanto, uma tendência marcada no sentido da redução dos teores de feldspato na direção do topo da coluna.

Uma análise detalhada das sequiências litoestratigráficas encontradas mostra imediatamente inúmeras convergências de comportamento, seja na composição litológica, seja na geometria dos contatos. Numa primeira constatação, verifica-se que os contatos entre as unidades se processam sempre de maneira erosiva. Hiatos erosivos ocorrem com relativa freqüência denunciando uma deposição descontínua também no decorrer do tempo. Em conseqüência, as unidades de caráter regional assumem grande importância na definição das seqüências litoestratigráficas, as quais, por sua vez, possibilitam o estabelecimento das primeiras correlações.

Dentro da seqüência litoestratigráfica considerada como de representatividade regional, são individualizados três sistemas distintos: $a$ ) seqüência coluvial inferior associada a solos bastante evoluídos e bem estruturados (estruturas secundárias ou pedológicas em blocos angulares ou subangulares) com coloração avermelhada mosqueada pelos óxidos de ferro. Este sistema inferior é representado pelas unidades Tebas e Triqueda; $b$ ) a seqüência intermediária é constituída por materiais coluviais que apresentam solos menos desenvolvidos (estrutura granular) e de coloração tendendo ao amarelo. Este sistema encontra-se representado até o momento pelas unidades Santos Dumont, Santa Bárbara e Guarará; c) seqüência superior, caracterizada pela ocorrência de sedimentos coluviais marrons e com pedogênese pouco desenvolvida, com estrutura granular incipiente. Encontra-se representada pela unidade Goianá e pelo colávio de cobertura. 
As seqüências quaternárias ocorrem sempre em inconformidade sobre o Pré-Cambriano alterado, sendo o contato basal freqüentemente marcado por concentração de rudáceos. Nas seções em que este contato se faz com a seqüência inferior, o plano de descontinuidade é acompanhado por concentração de seixos angulosos de litologias variadas (linhas de seixos). Quando a seqủência média jaz diretamente sobre o PréCambriano, o contato erosivo é, em algumas seções, delineado por concentrações mais espessas de seixos rolados de quartzo (cascalheiras).

Lentes de seixos rolados de quartzo têm recorrência freqüênte e ocupam posições bem definidas dentro da coluna litoestraćigráfica em elaboração, especialmente no domínio dá seqüência intermediária. A presença ou inexistência destas cascalheiras nas seçoes levantadas não parece, no entanto, ser um problema a ser explicado por considerações de cunho puramente estratigráfico no estágio atual da pesquisa: as concentraçóes de quartzo rolado resultam de uma dinâmica de sedimentação localizada, associada à presença de antigos canais de drenagem. A amostragem das seções, preferencialmente na meia encosta, tende a tornar aleatório o aparecimento destes depósitos ligados ao ambiente fluvial.

Todos os contatos erosivos entre as diferentes unidades tendem a ser acompanhados por alinhamentos, geralmente descontínuos, de clásticos mais grosseiros (variando o diâmetro de grão entre poucos milímetros e vários centímetros) e de litologias variáveis com predomínio de quartzo. Partindo-se da conceituação de "linha de seixos" de Parizek e Woodruff (1957) ocorrem, portanto, linhas de seixos e também linhas de grânulos. A observação de concentrações de grosseiros com diâmetro de grão os mais variados leva a uma série de questionamentos no que se refere às teorias clássicas de interpretação do significado paleoclimático destas feições.

CONCLUSÕES No presente estudo foram individualizadas três seqüências coluviais em que os contatos intra e interseqüências de unidades são sempre erosivos, mostrando truncamentos que se sucedem dos interflúvios ao eixo dos anfiteatros. A representação das seções à meia-encosta e em cortes transversais aos anfiteatros (hollows) possibilitou a detecção de um maior número de testemunhos materiais da evolução, promovendo ainda uma relativa homogeneização das seqüências deposicionais. Entretanto, para uma reconstituição mais completa dos eventos do Quaternário Superior, fazßse necessário a interação de estudos nos ambientes de encostas (rampas) e fluviais (terraços). Estudos anteriores (Meis e Monteiro, 1979; e Machado, inédito) em ambiente de transição dos domínios de encostas e fluvial demonstraram a ocorrência de uma interdigitação entre as seqüências sedimentares a eles associadas.
A problemática que envolve o mecanismo de sedimentação em ambiente de encosta limita a priori qualquer inferência paleoclimática para os resultados obtidos; os indicadores paleoambientais convencionais mostram-se insuficientes para o estabelecimento de relaçőes cronoestratigráficas. Por exemplo, as cascalheiras de quartzo rolados representam quase sempre unidades provenientes de retrabalhamentos de depósitos aluviais mais antigos. Com efeito, são constituídas por um percentual de seixos subangulosos ao lado de outros arredondados e seu caráter recorrente é documentado por sua presença em diferentes posições da coluna litoestratigráfica. Por outro lado, as linhas de seixos, se tomadas isoladamente, podem apenas testemunhar as fases erosivas que acompanham praticamente todos os contratos.

Numa tentativa de melhor posicionar as sequiências obtidas para os depósitos de encosta do médio-baixo vale do Paraíba do Sul procurou-se estabelecer ainda algumas correlações preliminares com as evidências já estudadas na bacia do rio Doce. A seqüência descrita como intermediária (unidades Santos Dumont, Santa Bárbara e Guarará) assim como parte da seqüência inferior ocorrem também no médio rio Doce.

No médio rio Casca, pesquisas de Machado (inédito) mostram que a unidade Triqueda é truncada pela Santos Dumont em cujo topo desenvolve-se um horizonte $\mathbf{A}$ orgânico (solo Ouro Fino). Este paleossolo é encontrado na seção de Guarará, onde ocupa a mesma posição estratigráfica e foi datado em $10105 \pm 275$ anos BP pelo C-14.

Em Naque (médio rio Doce), o solo Ouro Fino justapõe-se aos depósitos argilosos lacustres do membro médio e é secionado pelas areias fluviais do membro superior da Formação Ipatinga (Paepe e Meis, inédito). É interessante notar, outrossim, que o membro lacustre da Formação Ipatinga, datado em $10340 \pm 190$ anos BP e $10220 \pm 225$ anos $\mathrm{BP}$, se encontra recoberto pelo colúvio Guarará.

Tendo como base os resultados geocronológicos do rio Doce, foi tentada uma primeira aproximação cronoestratigráfica para as seqüências coluviais do médiobaixo vale do rio Paraíba do Sul. Nesta fase inicial do trabalho prefere-se, por enquanto, abordar a cronoestratigrafia a nível de Série. Assim sendo, a Série Pleistocênica englobaria, em princípio, a parte inferior da seqüência litoestratigráfica considerada aqui como intermediária. Esta última seria transgressiva no tempo, prolongando-se pelo Holoceno.

Agradecimentos Os autores desejam expressar seus agradecimentos ao Professor Josué Camargo Mendes pela revisão e sugestões fornecidas ao presente trabalho, e aos bolsistas Tácio José de Oliveira da Silva e Marietta Paim pela colaboração nas diferentes fases da pesquisa. 


\section{BIBLIOGRAFIA}

AB'SABER, A. N - 1962 - Revisão dos conhecimentos sobre o horizonte subsuperficial de cascalhos inhumados do Brasil Oriental. Bol. Univ. Paraná Geogr. Fis, 2: 2-32.

ALMEIDA, F F M. HASUI, Y - e CARNEIRO, C. D. R. - 1976 - Lineamento de Além Paraíba. Anais da Academia Brasileira de Ciências $47(3 / 4)$.

ASMUS, H. E. e FERRARI, A. L. - 1978 - Hipóteses sobre a causa do tectonismo Cenozóico na regiąo sudeste do Brasil. In; Aspectos estruturais da margem continental leste e sudeste brasileira. Série projeto REMAC 4: 7-24.

BIGARELLA, J. J. - 1964 - Variaçðes climáticas no Quarternário e suas implicaçðes no revestimento floristico do Paraná. Bol. Paran. Geogr. 10/15: 211.223:

BIGARELLA, J. J.; MOUSINHO, M. R.; e SILVA, J. X. - 1965-Processes and Environments of the Brazilian Quaternary. Simposium on cold climate processes and Environments, VII INQUA Congress, Fairbanks, Imp. Univ. do Paraná.

- BRANDALISE, L. A.; RIBEIRO, J. H.; e FERRARI, P. G. - $1976-$ Relatorio Final (inéditos). Projeto Vale do Paraiba do Sul. Belo Horizonte, CPRM, $411 \mathrm{pp}$.

BROWN, JR. L S, AB'SABER, A, N - 1979 - Ice-Age forest refuges and evolution in the Neotropics: correlation of paleoclimatological geomorphological and pedological data with modern biological endesmism. Paleoclimas 5: $19 \mathrm{pp}$.

DE MARTONNE, E. - 1943 - Problemas morfológicos do Brasil Tropical Atlântico. Rev. Bras. Geogr. 5 (4): 532-550.

FAIRBRIDGE, R. W. - 1969 - Quaternary Period. In: Encyclopedia of Geomorphology. R. W. Fairbridge (ed.), Reinhold Book Co., 912-931.

FLINT, R.F. - 1965 - The Quaternary|System in the Quaternary. Vol. I, Ka lervo Pankama (ed.), Interscience Publ, Nova York.

FREITAS, R. O - 1951 - Ensaio sobre o relevo tectônico do Brasil. Rev. Bras. Geogr. 13: 171-222.

HASUI, Y.; SADOWSKI, G. R.; e CARNEIRO, C. D. R. - 1976 - Consideraçðes sobre a estratigrafia doPrecambrianoino Estado de São Paulo. Bo IG 9 USP: 107-113.

KING, L. C. - 1956 - A geomorfologia do Brasil Oriental. Rev. Bras, de Geo grafia $18(2)$ : $147-266$.

LEHMANN, H. - 1957 - Klimamprphologische Besbachtungen in der Serra da Mantiqueira und in Paraiba Tal. Geom. Abh. 5, Univ. Berlim: 67-72.
MEIS, M. R. M.; MACHADO, M. B.; e CUNHA, S. B. -1975 - Note on the distribution and origin of Late Quaternary ramps near Rio de Janeiro. An. Acad. Bras. Ciências 47 (supl.)

MEIS, M. R. M. e MONTEIRO, A. M. F. - 1979 - Upper Quaternary Ramps: Doce river valley, Southeastern Brazilian plateau. Zeitschrift fü Geomorph. 23 (2): 131-151.

MORRISON, B. R. - The Pleistocene-Holocene boundary: an evaluation of the various criteria used for determining it on a provicial basis and suggestions for establishing (inédito).

MOUSINHO, M. R. e BIGARELLA, J. J. - 1965 - Movimentos de massa no transporte dos detritos da meteorizaça das rochas. Bol. Paran. Geogr. 16/17: $43-48$

OJUNAGA, A. G. e WIRTH, K. - 1977 - Threefold stone lines in Southwestern Nigeria: evidence of cyclic soil and landscape development, Soil Science 123: $249-257$.

PARIZEK, E. J. e WOODRUFF, J. F. - 1957 - Description and origin of stone layers in soils of the southeastern States. J. Geol. 65: 24-34.

PENTEADO, M. M. - 1969 - Novas informaçðes a respeito dos pavimentos detriticos ("storn lines"). Not. Geomorf. 17: 15-41.

PETTIJOHN, F, J. -1957 m Sedimentary rocks. Harper and Bros., New York, $718 \mathrm{pp}$

PFLUG, R. - 1969 - Quaternary lakes of Eastern Brazil. Photogrammetria 24: $29-35$.

RUELLAN, G. F. - 1951 - Problemas do relevo e da estrutura do Brasil. Bol. Geogr. 102: 620-624.

SETZER, J. - 1949 - Os solos do Estado de Săo Paulo. C.N.G., IBGE.

TRICART, J, e CAILLEUX, A. - 1959 - Zonas fitogeográficas e morfoclimáticas do Quaternário no Brasil. Not. Geom. 4: 12-17.

TROLL, C. - 1969 - Inhalt, Problema und methoden Geomorphologischer Forschung Beih. Geol. Jb. 80: 225-257.

WASHBURNE, C. W. - 1939 - Geologia do petróleo do estado de São Paulo. Min. Agric. DNPM: $228 \mathrm{pp}$.

WILLMAN, H. B. e FRYE, J. C. - 1970 - Pleistocene Stratigraphy of Iltjnois. Illinois State Geol. Survey Bull. 94: $204 \mathrm{pp}$.

ZONNEVELD, J. I. S. - 1975 - Some problems of Tropical Geomorphology. Geomorph. N. F, 19/4:377.392.

Recebido em 25 de setembro de 1980 